\title{
Physical Fitness and Cardiopulmonary Baroreflex to Passive Head-up Tilt
}

\author{
Haruki Hayashi' ${ }^{1)}$, Kazuya Matsuda ${ }^{2)}$, Noritoshi Yoshitsugu ${ }^{3)}$ \\ and Haruhiko Sato ${ }^{1)}$ \\ 1) Department of Ergonomics, Kyushu Institute of Design \\ 2) Industrial Design Division, Minolta Co., Ltd. \\ 3) Interior Development Section, Technical Center, Nissan Motor Co., Ltd.
}

\begin{abstract}
The relationship between physical fitness and cardiopulmonary $(\mathrm{CP})$ baroreflex induced by the decrease in venous return was inveștigated. Maximal oxygen uptake / lean body mass $\left(\dot{\mathrm{VO}}_{2 \max } / \mathrm{LBM}\right)$ was used as a measure of physical fitness. CP baroreflex was examined in 8 subjects $[22.0 \pm 2.0(\mathrm{SD}) \mathrm{yr}]$ ranging from low $\left(47.3 \mathrm{ml} \cdot \mathrm{kg}^{-1} \cdot \mathrm{min}^{-1}\right)$ to highly $\left(72.6 \mathrm{ml} \cdot \mathrm{kg}^{-1} \cdot \mathrm{min}^{-1}\right)$ fit subjects who were exposed to the orthostatic load using passive head-up tilt. Tilting from $0^{\circ}$ to $70^{\circ}$ in $10^{\circ}$ increments was applied. Each tilting was preceded by measurements at the basal position of $0^{\circ}$. Heart rate, systolic and diastolic pressure, stroke volume, and forearm blood flow were measured before and during tilting; Cardiac output, mean arterial pressure, and forearm vascular resistance (FVR) were calculated. FVR was increased with the raising in tilt angle in each subject, but the onset of increase in FVR tended to be earlier in proportion to the higher level of physical fitness. There is a negative and significant correlation between the onset of increase in FVR and $\dot{V O}_{2 \max } / \mathrm{LBM}$. The physically fit subject exhibited a more rapid onset of an increase in FVR to orthostatic stress than the unfit subject. Thus the higher the physical fitness, the lower the threshold in $\mathrm{CP}$ baroreflex response.
\end{abstract}

(Appl Human Sci, 14(4): 167-176, 1995)

Keywords: cardiopulmonary baroreflex, physical fitness, head-up tilt

\section{Introduction}

During the postural change from supine to upright, blood is accumulated in lower part of the body, especially in venous system, due to the hydrostatic effect. It gives rise to reduction of central venous pressure (CVP) in accordance with decreased venous return. This pressure change detected by cardiac or pulmonary mechanoreceptors, results in peripheral or visceral vasoconstriction and increase in heart rate to maintain cardiac output. Maintenance of cardiac output under the condition which causes the reduction of venous return is one of the important abilities in cardiovascular system. Cardiopulmonary (CP) baroreflex acts a part of this responses. An index of the responsiveness of the $\mathrm{CP}$ baroreflex is defined as the increase in forearm vascular resistance (FVR) during the decrease in CVP (Mark and Mancia, 1983). It is reported that baroreflex control of FVR during orthostatic stress is attenuated in physically fit individuals (Mack et al., 1987; 1993; Raven et al., 1984). On the other hand, there are several evidences that physically fit individuals have an increased (Takeshita et al., 1986) or slightly increased or no changed (Convertino et al., 1984; Lightfoot et al., 1989) CP baroreflex. It seems to suggest that there is a certain interaction between FVR in response to reduction of CVP and physical fitness. Exercise training produces a bradycardia in resting or submaximal exercise (Clausen et al., 1973) and a blood volume expansion (Convertino, 1991). These adaptations are thought to yield a good response to any stress. It cannot be assumed that there are no advantages in exhibiting a good response in $\mathrm{CP}$ baroreflex to orthostatic stress in physically fit individuals. Recently, Convertino (1993) noted that blood pressure regulatory response is not attenuated by exercise training that maintains maximal oxygen uptake $\left(\mathrm{VO}_{2 \max }\right)$ below $55-60 \mathrm{ml} \cdot \mathrm{kg}^{-1} \cdot \mathrm{min}^{-1}$ and blood volume expansion less than $15 \%$. Furthermore, this problem is not only in the orthostatic challenge concerned but also from redistribution of the blood in the exercising condition, especially under the hot environment (Nadel et al., 1979). The increase in skin blood flow due to vasodilatation of subcutaneous vessels as well as the decrease in plasma volume accompanied by sweating cause the reduction of venous return. In order to secure adequate muscle blood flow for exercising, the reflex vasoconstriction in the skin will occur at the expense of the body temperature regulation to some extent. In these conditions of venous pooling, $\mathrm{CP}$ baroreflexes contribute to the maintenance of arterial pressure during mild exer- 
Table 1 Physical and physiological characteristics of subjects.

\begin{tabular}{|c|c|c|c|c|c|c|c|c|c|}
\hline Subj. & $\begin{array}{l}\text { Age } \\
(y r)\end{array}$ & $\begin{array}{c}\text { Height } \\
(\mathrm{cm})\end{array}$ & $\begin{array}{c}\text { Weight } \\
(\mathrm{kg})\end{array}$ & $\begin{array}{l}\mathrm{BSA} \\
\left(\mathrm{m}^{2}\right) \\
\end{array}$ & $\begin{array}{c}\% \mathrm{Fat} \\
(\%)\end{array}$ & $\begin{array}{l}\text { LBM } \\
(\mathrm{kg})\end{array}$ & $\begin{array}{l}\mathrm{V} \mathrm{O}_{2 \max } \\
(1 / \mathrm{min}) \\
\end{array}$ & 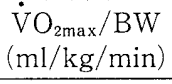 & $\begin{array}{l}\dot{\mathrm{V}} \mathrm{O}_{2 \max } / \mathrm{LBM} \\
(\mathrm{ml} / \mathrm{kg} / \mathrm{min})\end{array}$ \\
\hline $\mathrm{NA}$ & 19 & 167.3 & 54.08 & 1.57 & 13.2 & 49.70 & 3.41 & 63.0 & 72.6 \\
\hline $\mathrm{KO}$ & 20 & 172.5 & 65.85 & 1.73 & 15.1 & 59.59 & 3.62 & 55.0 & 64.8 \\
\hline SU & 23 & 172.2 & 66.90 & 1.78 & 18.1 & 59.01 & 3.44 & 51.4 & 62.7 \\
\hline $\mathrm{FU}$ & 23 & 177.4 & 60.42 & 1.70 & 16.9 & 52.75 & 2.91 & 48.1 & 57.9 \\
\hline IS & 24 & 164.1 & 60.70 & 1.62 & 19.1 & 54.27 & 2.53 & 41.7 & 51.5 \\
\hline $\mathrm{OK}$ & 23 & 182.8 & 74.93 & 1.91 & 18.3 & 65.34 & 3.15 & 42.0 & 51.4 \\
\hline $\mathrm{KA}$ & 22 & 176.7 & 66.40 & 1.68 & 22.7 & 55.71 & 2.62 & 39.4 & 51.0 \\
\hline $\mathrm{TU}$ & 23 & 163.8 & 62.20 & 1.63 & 18.4 & 54.36 & 2.40 & 38.6 & 47.3 \\
\hline Mean & 22 & 171.0 & 63.94 & 1.70 & 17.7 & 56.34 & 3.01 & 47.4 & 57.4 \\
\hline S.D. & 2 & 6.2 & 5.73 & 0.10 & 2.6 & 4.53 & 0.44 & 8.1 & 8.1 \\
\hline
\end{tabular}

BSA: Body surface area

\%Fat: Percentage of body fat

BW: Body weight

LBM: Lean body mass

$\mathrm{VO}_{2 \max }$ : Maximal oxygen uptake

cise in human subjects (Mack et al., 1988).

It seems plausible to postulate that the human being has universally acquired the response of cardiovascular adjustment to orthostatic challenge. However, individually, there may be a much wider variation of its adaptation depending on both the endogenous and exogenous condition that one underwent. In the light of modern sedentary working environment, the importance of adaptation to static cardiovascular response has been an increasing concern recently. Examining the relationship between physical fitness and CP baroreflex may give a clue in elucidating static cardiovascular adaptation. In the present study, we have examined the $\mathrm{CP}$ baroreflex in subjects ranging from low to highly fit individuals who were exposed to the orthostatic load using passive tilt.

\section{Methods}

Eight healthy college students varying in age from 19 to 24 yr without past history of cardiovascular disease were selected for this study. Physical characteristics of the subjects are given in Table 1.

Body surface area (BSA) was estimated using following equation introduced by Fujimoto et al. (1968):

BSA $\left(\mathrm{m}^{2}\right)=\mathrm{W}^{0.444}(\mathrm{~kg}) \times \mathrm{H}^{0.663}(\mathrm{~cm}) \times 0.008883$

where $\mathrm{W}$ is body weight, and $\mathrm{H}$ is height (stature).

Body fatness was estimated from skinfold thickness determined at 2 sites (triceps and subscapular) using a skinfold caliper (Meikosha). Body density and percent body fat were estimated using the equations of Nagamine and Suzuki (1964) and Broźek et al. (1963), respectively (Table 1). These characteristics of subjects were included in standard levels of Japanese men of the same age.

$\mathrm{VO}_{2 \max }$ was used as a measure of maximal aerobic capacity. $\mathrm{VO}_{2 \max }$ was determined during graded treadmill walking or jogging as described by Balke (1961).
The criteria used to document that $\dot{\mathrm{V}}_{2 \max }$ had been attained during each test were, 1) lack of increase in $\mathrm{O}_{2}$ uptake with increase in work rate (leveling off criterion), 2) respiratory exchange ratio $\left(\mathrm{CO}_{2}\right.$ production $/ \mathrm{O}_{2}$ uptake) $>1.1$, and 3) attainment of the maximal heart rate reached more than 180 . Maximal oxygen uptake per kilogram of body weight $\left(\dot{\mathrm{V}}_{2 \max } / \mathrm{BW}\right)$ and lean body mass $\left(\mathrm{VO}_{2 \max } / \mathrm{LBM}\right)$ were calculated (Table 1$)$. In order to minimize the effect of the different physical characteristics of each subject, we adopted the $\mathrm{VO}_{2 \max }$ normalized by lean body mass for further analysis.

Head-up tilt was used to induce an unloading of $\mathrm{CP}$ baroreceptors. The subject was tilted from $0^{\circ}$ to $70^{\circ}$ in $10^{\circ}$ increments. The table was tilted at a rate of about $1^{\circ}$ $\mathrm{sec}^{-1}$. The subject was assigned to rest quietly in the supine position on a tilt table for 20 minutes before the experiment. Measurements at angle of $10^{\circ}$ through $70^{\circ}$ were preceded by measurements at the basal position of $0^{\circ}$. The subject remained in each tilt angle position for 5 minutes. Three minutes rests $\left(0^{\circ}\right.$ tilt $)$ were intervened between tilting. Systolic (SBP) and diastolic (DBP) blood pressures, Forearm blood flow (FBF), and Stroke volume (SV) were measured 5 times during the last 5 minutes of supine rest, 5 times during tilting and 3 times during the intervening rest period, at 1 minute intervals.

Heart rate (HR) was calculated from electrocardiogram with the output recorded on a strip chart recorder. SBP and DBP were measured by auscultatory cuff method using an electrosphygmomanometer (OMRON, model HEM-719K). Mean arterial blood pressure (MAP) was calculated as one-third pulse pressure plus DBP. SV was measured noninvasively by impedance cardiography (IFM Impedance Cardiograph, model 400) from four silver tape electrodes placed around the neck (two) and thorax (two) as described by Kubicek et al. (1966). Cardiac output (CO) was calculated from the product of $\mathrm{SV}$ and $\mathrm{HR}$.

FBF was measured by venous occlusion plethys- 

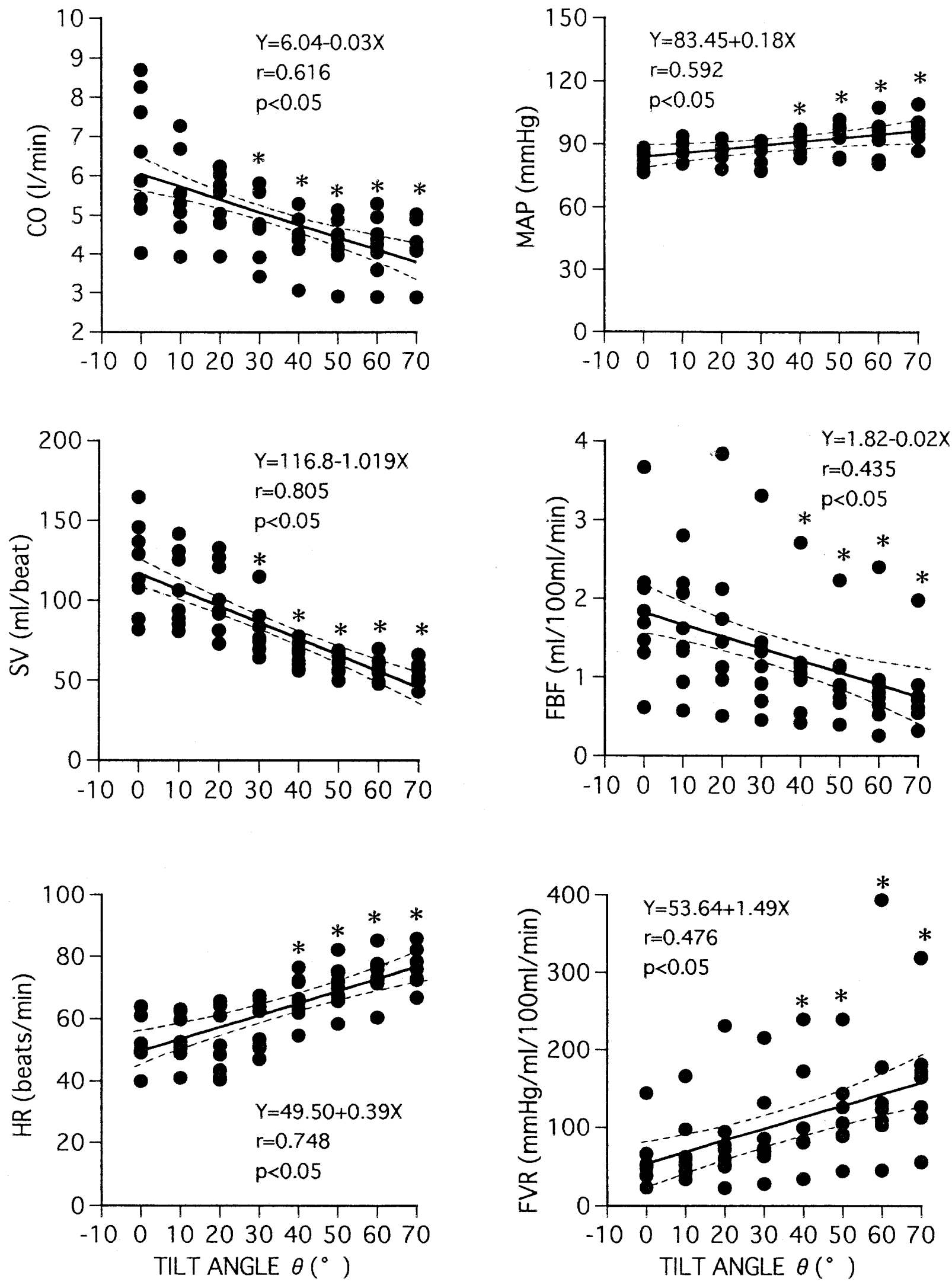

Fig. 1 Cardiac output (CO), stroke volume (SV), heart rate (HR), mean arterial blood pressure (MAP), forearm blood flow (FBF), and forearm vascular resistance (FVR) responses to rest and passive head-up tilt from tilt angles $(\theta)$ of $10^{\circ}$ to $70^{\circ}$ in 8 subjects. The regression line (solid line) with $95 \%$ confidence limits to regression estimates (broken lines) were shown in each circulatory variable $(\mathrm{p}<0.05)$. Asterisks $(*)$ denote the tilt angle that shows a statistically significant difference from $\theta=0^{\circ}(\mathrm{p}<0.05)$. 


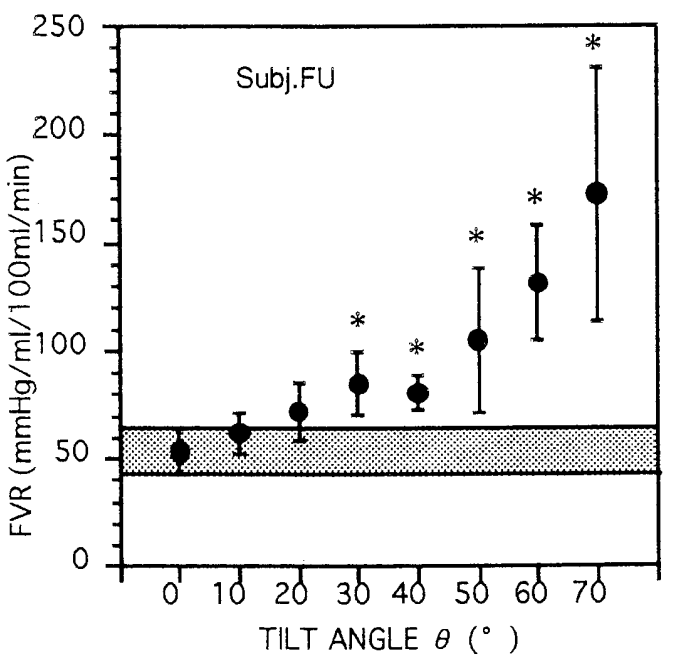

Fig. 2 Representative data of forearm vascular resistance (FVR) in each tilt angle $(\theta)$ for subject FU. Each point and bar represents mean and $\mathrm{SD}$, respectively. The shaded area shows the range of mean $\pm 1 \mathrm{SD}$ of $\mathrm{FVR}$ at $\theta=0^{\circ}$. Asterisks $(*)$ denote the data that show a statistically significant increase away from the FVR at $\theta=0^{\circ}$.

mography, using a mercury-filled silastic strain gauge applied at proximal one-third of the right forearm (Whitney, 1953) and forearm vascular resistance (FVR) was calculated by dividing MAP by FBF. The right arm was held in the horizontal position at any angle of tilt table.

All these measurements were taken at a constant room temperature $\left(28^{\circ} \mathrm{C}\right)$ and relative humidity $(50 \%)$ in an artificial climatic chamber.

The value of circulatory variables for each subject at the supine rest and at each tilt angle was the average of the five measurements.

Least-square regression analysis was used to define the form of the relationship between variables. The correlation coefficients ( $r$ ) for the linear regressions were calculated by the Pearson product-moment equation. The significance of regression was tested by using Student's t test. Analysis of covariance was used to test for significant difference between two regression slopes. Wilcoxon's test was performed on circulatory variables to test for differences between rest and each tilt angle. The $5 \%$ probability level was used for evaluating the statistical significance.

\section{Results}

Hemodynamic responses to tilting from $0^{\circ}$ to $70^{\circ}$ are shown in Fig. 1. CO, SV, and FBF tended to decrease, whereas HR and MAP slightly increased, while FVR considerably increased with the increased tilt angle. The data at tilt angles from $30^{\circ}$ through $70^{\circ}$ for $\mathrm{CO}$ and $\mathrm{SV}$, and also from $40^{\circ}$ through $70^{\circ}$ for $\mathrm{HR}, \mathrm{MAP}, \mathrm{FBF}$, and FVR are significantly different from those at rest $(\mathrm{p}<$

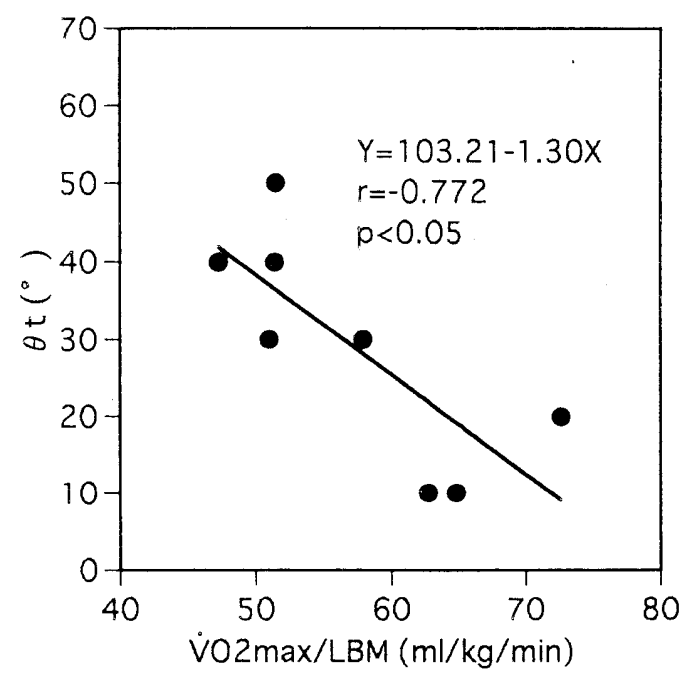

Fig. 3 Relationship between maximal oxygen uptake / lean body mass $\left(\dot{V}_{0_{2 m a x}} / \mathrm{LBM}\right)$ and the tilt angle $(\theta \mathrm{t})$ that shows a statistically significant increase away from the forearm vascular resistance (FVR) at $\theta=0^{\circ}$.

0.05). There were no syncopal symptoms throughout the experiment. However, at $70^{\circ}$ tilt, subject $\mathrm{KO}$ wanted to terminate the experiment for subjective reasons without any apparent dizziness or nausea. This lack of data at $70^{\circ}$ tilt did not affect the following analyses.

If the onset of an increase in FVR, i.e., the threshold (or sensitivity), is determined and has a distinctive feature in that it tends to be influenced by individual variations, the relationship between these threshold and physical fitness should provide one of the evaluations of cardiovascular adaptation.

The tilt angle $(\theta t)$ that shows a statistically significant increase away from the FVR at $0^{\circ}$ of tilt angle is determined as the onset of increase in FVR in each subject. Figure 2 depicts the manner of analysis for one subject. There is a negative and significant correlation between this angle $(\theta \mathrm{t})$ and $\mathrm{VO}_{2 \max } / \mathrm{LBM}(\mathrm{r}=-0.772, \mathrm{p}<$ 0.05) (Fig. 3). However, $\theta$ t is obtained only in every 10 degrees of tilt angle. Thus, within the limits of these selected angles that show a statistically significant change from $\mathrm{FVR}$ at $0^{\circ}$ of tilt angle, regression analysis between the percent change of FVR $(\Delta \% \mathrm{FVR})$ and the tilt angle $(\theta)$ was made for each subject. There was a linear relationship between $\Delta \% \mathrm{FVR}$ and $\theta$ in each subject (Fig. 4). The point where this regression line intersects the line of $\Delta \% \mathrm{FVR}=0$ is defined as critical tilt angle $(\mathrm{C} \theta)$. The point just beyond the critical tilt angle is thought to be the threshold of increase in FVR. Since this critical value reflects the threshold, it was regarded as the threshold of the $\mathrm{CP}$ baroreflex response in the following description. The slope of the regression line of $\triangle \% \mathrm{FVR}$ on $\theta$ is defined as the responsiveness $(\mathrm{S} \theta)$ of the CP baroreflex. There is a negative and statistically significant correlation between $\mathrm{C} \theta$ and $\dot{\mathrm{VO}}_{2 \max } / \mathrm{LBM}(\mathrm{r}=-0.818, \mathrm{p}<0.05)$ (Fig. 5(a)). On the other 


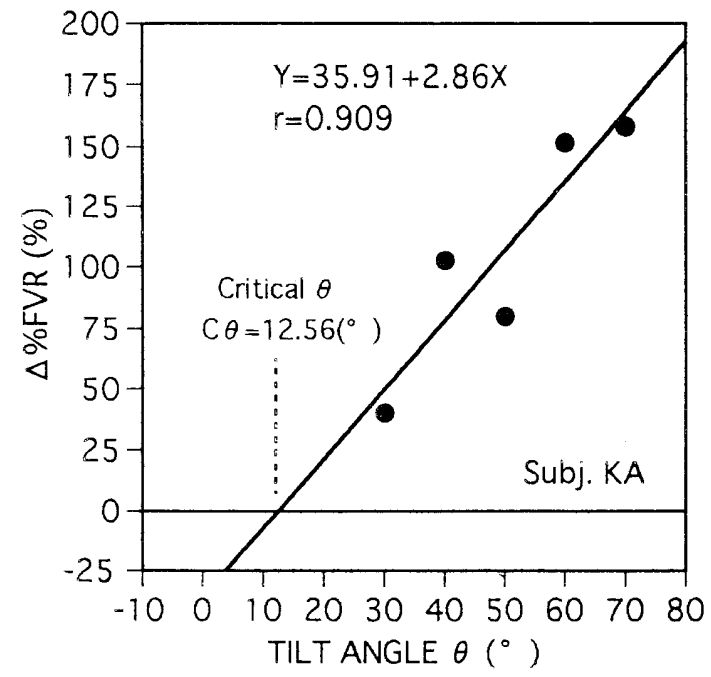

Fig. 4 Relationship between the percent change of forearm vascular resistance $(\mathrm{FVR})(\triangle \% \mathrm{FVR})$ and the tilt angle $(\theta)$ for subject KA. The critical tilt angle $(\mathrm{C} \theta)$ to $\Delta \% \mathrm{FVR}$ is extrapolated from the regression analysis. The slope of regression line is defined as the responsiveness of increase in FVR $(\mathrm{S} \theta)$.

hand, no significant correlation was found between $\mathrm{S} \theta$ and $\mathrm{VO}_{2 \max } / \mathrm{LBM}$ (Fig. 5(b)). However, the results obtained for $\mathrm{C} \theta$ are difficult to interpret, because some of these critical tilt angles have negative values. It means that the $\mathrm{C} \theta$ was found in the range of head- down tilt. Then, it seems pertinent to introduce the changes in $\mathrm{SV}$ instead of the tilt angle. The percent change in FVR $(\triangle \% \mathrm{FVR})$ is plotted against the percent change in SV $(\Delta \% \mathrm{SV})$ (Fig. 6). The slope of the regression line of $\Delta \%$ FVR on $\Delta \% \mathrm{SV}$ is defined as the responsiveness (Ssv) of the $\mathrm{CP}$ baroreflex and also the intercept of the line at zero $\Delta \% \mathrm{FVR}$ is defined as critical $\Delta \% \mathrm{SV}$ (Csv). There is a positive and statistically significant correlation

Table 2 The critical value of tilt angle $(\mathrm{C} \theta)$ and of percent change in stroke volume (Csv) to percent change in forearm vascular resistance ( $\triangle \% \mathrm{FVR})$, and the responsiveness of $\Delta \% \mathrm{FVR}$ to tilt angle ( $\mathrm{S} \theta$ ) and to percent change in stroke volume (Ssv) in each subject.

\begin{tabular}{crrrr}
\hline Subj. & $\mathrm{C} \theta$ & $\mathrm{S} \theta$ & Csv & Ssv \\
\hline NA & -21.96 & 1.74 & 16.75 & -2.24 \\
KO & -7.40 & 3.04 & 36.64 & -1.74 \\
SU & 8.15 & 1.92 & 7.96 & -2.17 \\
FU & 22.39 & 4.20 & -6.48 & -2.95 \\
IS & 16.30 & 2.74 & -10.29 & -3.70 \\
OK & 2.57 & 2.80 & -51.52 & -14.70 \\
KA & 12.56 & 2.86 & -22.46 & -4.50 \\
TU & 29.62 & 6.21 & -38.80 & -14.90 \\
\hline
\end{tabular}

$\mathrm{C} \theta\left({ }^{\circ}\right)$ : Critical tilt angle to percent change in forearm vascular resistance $(\triangle \% \mathrm{FVR})$

$\mathrm{S} \theta\left(\% /{ }^{\circ}\right)$ : Slope of regression line for $\Delta \% \mathrm{FVR}$ to tilt angle $(\theta)$

Csv (\%) : Critical percent change in stroke volume to $\Delta \% \mathrm{FVR}$

Ssv : Slope of regression line for $\Delta \% \mathrm{FVR}$ to percent change in stroke volume $(\Delta \% \mathrm{SV})$
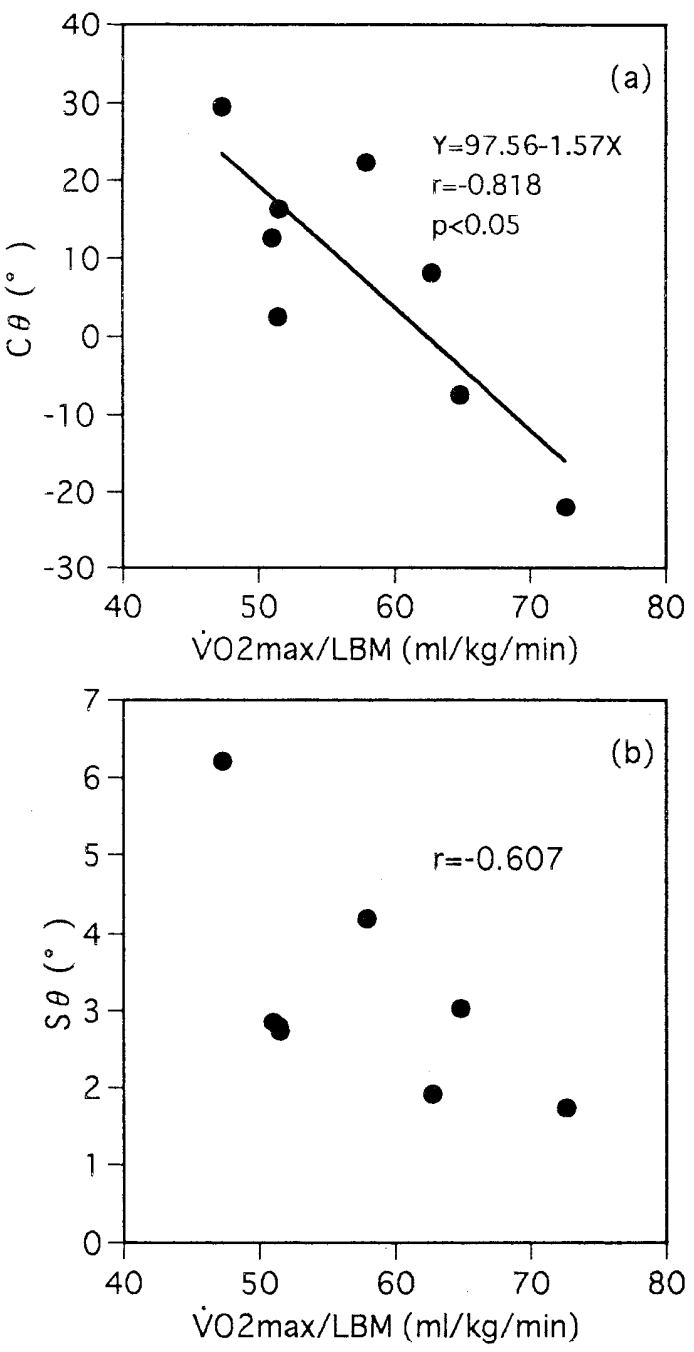

Fig. 5 (a): The relationship between $\dot{\mathrm{V}}_{\mathrm{O}_{2 m a x}} / \mathrm{LBM}$ and $\mathrm{C} \theta$. There is a negative and significant correlation between these two variables. (b): The relationship between $\mathrm{V}_{O_{2 \max }} / \mathrm{LBM}$ and $\mathrm{S} \theta$. There is no significant correlation between these two variables.

between Csv and $\dot{\mathrm{VO}}_{2 \max } / \mathrm{LBM}(\mathrm{r}=0.831, \mathrm{p}<0.05)$ (Fig. $7(\mathrm{a}))$. There is, however, no significant correlation between Ssv and $\dot{V O}_{2 \max } / \mathrm{LBM}$ (Fig. 7(b)). Thus, the higher the physical fitness, the lower the critical value in $\mathrm{SV}$ for $\mathrm{CP}$ baroreflex response. Table 2 lists $\mathrm{C} \theta, \mathrm{S} \theta$, $\mathrm{Csv}$, and Ssv in each subject.

\section{Discussion}

During the passive head-up tilt or lower body negative pressure (LBNP), the venous pooling occurs in lower limb. When the blood accumulation is prolonged, arterial blood pressure is maintained primarily by reflex tachycardia and splanchnic or forearm vasoconstriction (Abboud and Thames, 1983). The maintenance of CO in response to orthostatic load does not always depend on an increase in HR. A slight reduction in SV was not well 


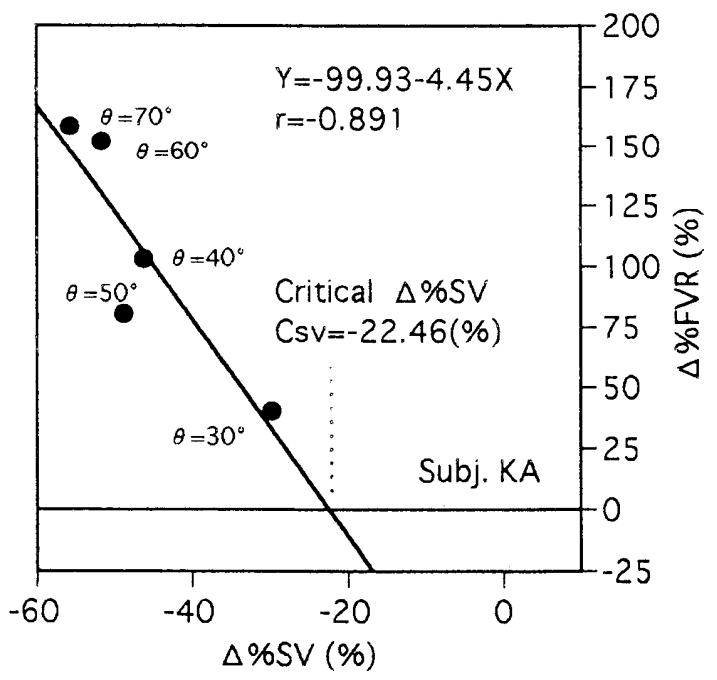

Fig. 6 The relationship between the percent change of FVR $(\Delta \%$ $\mathrm{FVR})$ and the percent change of SV $(\Delta \% \mathrm{SV})$ for subject $\mathrm{KA}$. The critical percent change in stroke volume (Csv) to $\Delta \%$ FVR is extrapolated from the regression analysis. The slope of regression line is defined as the responsiveness of increase in FVR (Ssv).

compensated for by an increase in HR. CP baroreflex is defined as the reflex originating from receptors in the cardiopulmonary region during diastolic state, i.e., relatively low pressure and regulating sympathetic activity to arterioles. This presumption is supported by the fact that ventricular deafferentation accompanied by cardiac transplantation causes a striking reduction in forearm vasoconstriction responses to LBNP (Mohanty et al., 1987). Head-up tilting or mild levels of LBNP cause venous return and cardiac filling pressure to decrease without detectable or significant changes in arterial blood pressure or heart rate. FVR is defined as one of the parameters of $\mathrm{CP}$ baroreflex.

Changes in SV are approximately linearly related to changes in CVP during decreased venous return (Nishiyasu et al., 1993). Thus, SV was used as an index of the level of $\mathrm{CP}$ mechanoreceptor activation.

Johnson et al. (1974) reported that LBNP applied as a ramp of $-1 \mathrm{mmHg} \cdot \mathrm{min}^{-1}$ yielded a gradual decline in right atrial pressure with stable $\mathrm{HR}$ and aortic pulse and mean pressure in the range of 0 to $-20 \mathrm{mmHg}$. There was a progressive decrease in FBF. These results have been considered a consequence of stimulation of low pressure receptors in the thorax and not due to arterial, i.e., high pressure, baroreceptor stimulation.

We observed the reduction of SV during head-up tilting. Blood pooling in lower limb caused a slightly increased $\mathrm{HR}$, augmentation of $\mathrm{FVR}$ as a result of a concomitant reduction in FBF, and maintaining MAP.

We cannot separate the contribution of low and high pressure baroreceptor reflexes from the data to the forearm vascular responses during high levels of venous pooling. However, if the increase in FVR at $70^{\circ}$ is
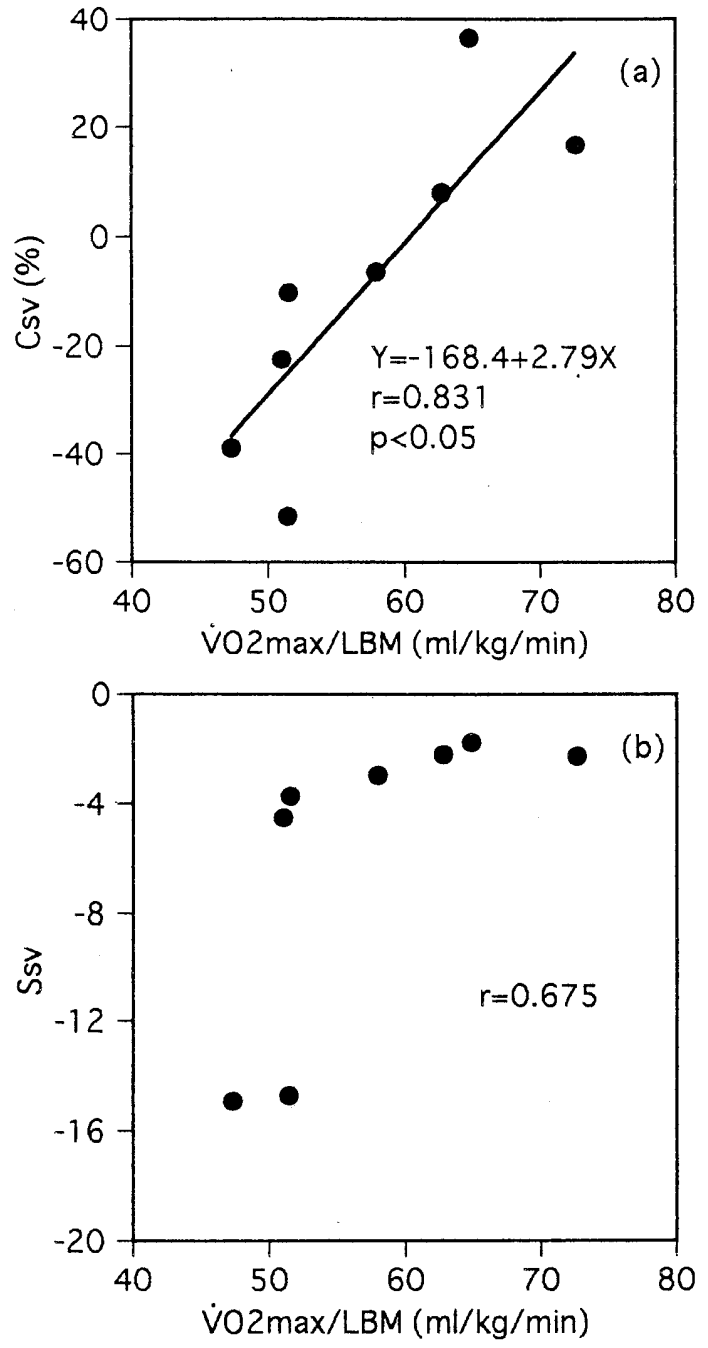

Fig. 7 (a): The relationship between $\dot{V O}_{2 \max } / \mathrm{LBM}$ and Csv. There is a positive and significant correlation between these two variables. (b): The relationship between $\dot{\mathrm{VO}}_{2 \max } / \mathrm{LBM}$ and Ssv. There is no significant correlation between these two variables.

considered as $100 \%$ of the vasoconstrictor responses, then $71 \%$ of the vasoconstriction occurred at $10^{\circ}$. Furthermore, the reflex that originate in low pressure baroreceptors may exert a dominant influence on forearm vascular tone at even high levels of venous pooling which are associated with decreases in arterial pressure and activation of high pressure baroreceptor reflexes (Zoller et al., 1972). Thus, the response of FVR in this study is considered to be CP baroreflex.

It has been reported that the change of increase in FVR $(\triangle F V R)$ was a linear function of the change of decrease in CVP $(\triangle \mathrm{CVP})$. The slope of the linear relationship between $\triangle F V R$ and $\triangle C V P$ was used as the gain of the CP baroreflex control of FVR. We investigated the relationship between $\mathrm{CP}$ baroreflex and physical fitness on the basis of assuming the threshold of increase in FVR together with the gain of CP baroreflex. 

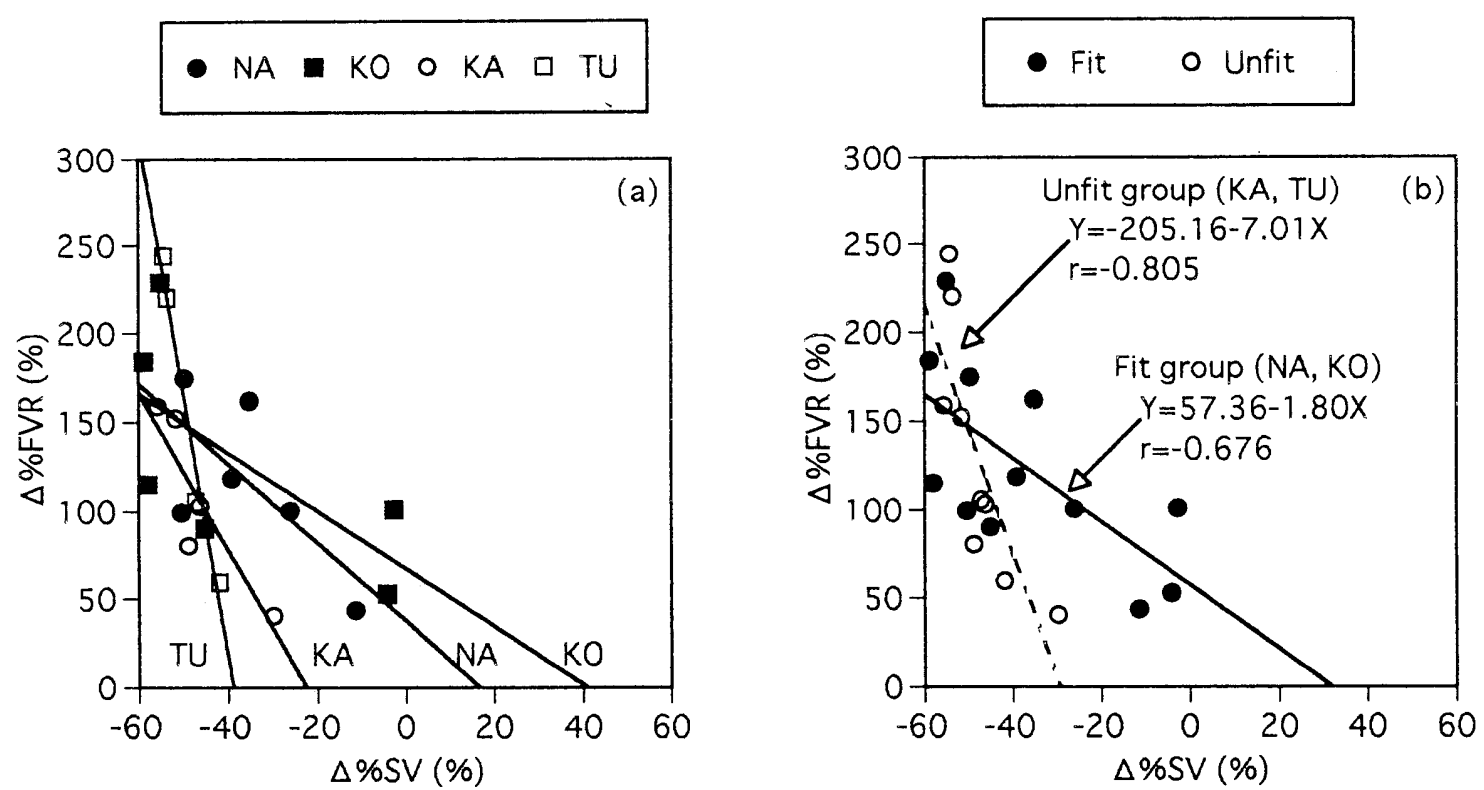

Fig. 8 (a):Responses of percent change in forearm vascular resistance $(\Delta \% \mathrm{FVR})$ to percent change in stroke volume $(\Delta \% \mathrm{SV})$, i.e., the slope (gain) of cardiopulmonary (CP) baroreflex in 4 subjects. The subjects with the highest and lowest aerobic power with respect to maximal oxygen uptake / body weight $\left(\dot{\mathrm{V}}_{2 \max } / \mathrm{BW}\right)$ were selected as fit group (NA, KO) and unfit group (KA, TU), respectively. Solid circles, solid squares, open circles, and open squares represent subject NA, KO, KA, and TU, respectively. Regression lines are denoted by each subject's abbreviation. (b): For convenience, the data of subjects NA and KO are pooled to give one group having high aerobic power (fit group) and subjects KA and TU are pooled to give another group having low aerobic power (unfit group). Solid circles represent fit group and open circles represent unfit group. Solid and broken lines represent the regression lines for the fit group and the unfit group, respectively. The slope of the unfit group is steeper than that of the fit group $(\mathrm{p}<0.05)$.

In this study, the onset, i.e., threshold, of increase in FVR $(\theta t)$ to orthostatic stress (tilt angle) was determined and correlated with physical fitness level (Figs. 2 and 3). However, $\theta \mathrm{t}$ was obtained at intervals of 10 degrees because of limitation in the experimental procedure. In order to settle this problem and to determine the gain, i.e., responsiveness, of the $\mathrm{CP}$ baroreflex, using the data that show a statistically significant change from FVR at $0^{\circ}$ of tilt angle (Fig. 2), regression analysis between the percent change in FVR $(\Delta \% \mathrm{FVR})$ and the tilt angle $(\theta)$ or the $\Delta \% \mathrm{FVR}$ and the percent change in $\mathrm{SV}(\Delta \% \mathrm{SV})$ were performed for each subject. These regression lines are intersected with the line of $\Delta \%$ $\mathrm{FVR}=0$. These intersections are defined as critical tilt angle $(\mathrm{C} \theta)$, and as critical percent change in SV (Csv) (Figs. 4 and 6). These critical values are treated as the threshold of CP baroreflex response.

The threshold of increase in FVR is lower in a physically fit subject than an unfit subject. Thus, a physically fit subject exhibited more rapid onset of response in ' $\mathrm{CP}$ baroreflex than an unfit subject.

Our result is in a sense in accord with previously reported result by Takeshita et al. (1986) that habitually exercising subject has a augmented FVR response as compared with non-exercising ones, but that is in contradiction to the findings of Mack et al. (1987) who reported - that physically fit subject (mean $\mathrm{VO}_{2 \max } / \mathrm{BW}=57.0 \pm$ $2.5 \mathrm{ml} \cdot \mathrm{kg}^{-1} \cdot \mathrm{min}^{-1}$ ) has a decreased FV.R response as compared with unfit subject (mean $\dot{\mathrm{V}}_{2 \max } / \mathrm{BW}=$
$38.5 \pm 3.0 \mathrm{ml} \cdot \mathrm{kg}^{-1} \cdot \mathrm{min}^{-1}$ ). In our study, if we selected 2 subjects each with the highest and the lowest aerobic power with respect to $\mathrm{VO}_{2 \max } / \mathrm{BW}$, subjects $\mathrm{NA}(63.0$ $\left.\mathrm{ml} \cdot \mathrm{kg}^{-1} \cdot \mathrm{min}^{-1}\right)$ and $\mathrm{KO}\left(55.0 \mathrm{ml} \cdot \mathrm{kg}^{-1} \cdot \mathrm{min}^{-1}\right)$ belong to the highest (fit) group and subjects KA $\left(39.4 \mathrm{ml} \cdot \mathrm{kg}^{-1}\right.$. $\left.\mathrm{min}^{-1}\right)$ and $\mathrm{TU}\left(38.6 \mathrm{ml} \cdot \mathrm{kg}^{-1} \cdot \mathrm{min}^{-1}\right)$ correspond to the lowest (unfit) group. The slope of the regression line of $\Delta \% \mathrm{FVR}$ on $\Delta \% \mathrm{SV}$ was $-2.24,-1.74,-4.50$, and -14.90 for subjects NA, KO, KA, and TU, respectively. Figure 8(a) depicts this relation. In order to clarify the difference between fit and unfit, the data of subjects NA and KO are pooled to give one group (fit) and subjects KA and TU another group (unfit). The slope of the regression line for unfit group is steeper than that for fit group (Fig. 8(b)). With respect to these extreme values in the slope, the physically fit subject reveals a diminished response of $\mathrm{CP}$ baroreflex as reported by Mack et al. $(1987 ; 1993)$. No significant findings were observed in the relationship between the responsiveness (slope) of $\mathrm{CP}$ baroreflex and physical fitness in this study (Figs. 5(b) and $7(\mathrm{~b}))$. This is probably due to the fluctuation in the data owing to a small sample size. According to Mack et al. (1987), when FVR is plotted against CVP, the former is linearly related to the latter, and negative relationship exists between these two variables in both fit and unfit groups. Then, the simple linear regression analysis with negative regression coefficient is applied. Thus the slope of unfit group is steeper than that of fit group. These regression lines intersect at a low FVR and a slightly 
reduced CVP point. Within the range of slightly decreased CVP, fit group has higher FVR compared to unfit group. The individual difference in FVR response may exists at the beginning of decrease in SV. It can reasonably be assumed that the threshold of increase in FVR should be introduced to elucidate the individual variation in the response of the $\mathrm{CP}$ baroreflex as well as the gain of the $\mathrm{CP}$ baroreflex, i.e., the slope of the linear relationship between FVR and SV, supposing the threshold of increase in FVR may reconcile conflicting evidence and divergent opinions.

It has been suggested that the response difference during orthostatic challenge is primarily caused by differences in autonomic control mechanisms (Raven et a1., 1984) rather than by difference in the degree of venous pooling. It is unlikely that there are differences between fit and unfit subjects in peripheral vascular reactivity (Svedenhag, 1985). The factors affecting CP baroreflex control could be as follows: Peripherally, it has been assumed that altered ventricular diastolic mechanics is associated with an acute increase in ventricular pressure and volume which is induced by endurance exercise training (Levine et al., 1991), and discharge characteristics of low pressure baroreceptors (Mifflin and Kunze, 1982) and high pressure baroreceptors (Kunze, 1985) itself. Convertinó (1993) concluded that $\dot{\mathrm{VO}}_{2 \max }$ per se does not contribute to orthostatic tolerance. It depends on the degree of blood volume expansion. There is no significant change in orthostatic stability until less than its 15\% increase. Since blood volume was not measured in this investigation, it is not clear whether the subject with high aerobic power has increased blood volume. However, there may not be at least any acute change in plasma volume or blood volume, because the subjects were not assigned to any physical exercise training before this experiment. If the exercise training is performed for a long period of time, it may result in some chronic adaptations for cardiovascular responses to orthostatic challenges.

Mechanoreceptors are known to be sensitive to extracellular $\mathrm{K}^{+}$and $\mathrm{Na}^{+}$concentrations. The threshold of the response to pressure is decreased and the sensitivity augmented by rising $\mathrm{K}^{+}$; a decrease in $\mathrm{Na}^{+}$ produces changes in the opposite direction (Saum et al., 1977). The increase in potassium concentration during tilt is augmented after 8 days cycle ergometer exercise at approximately $50 \% \dot{\mathrm{VO}}_{2 \max }$ (Shvartz et al., 1981). The increase in total circulating plasma levels of electrolytes associated with plasma and blood volume expansion is observed during endurance exercise training (Convertino, 1991). It contributes to shifting the stimulusresponse relationship to a lower operational range of $\mathrm{SV}$, i.e., the decreased threshold of increase in FVR at a given reduction of SV. Moreover, these findings of plasma electrolytes explain in part the augmented sensi- tivity (gain) of $\mathrm{CP}$ baroreflex in physically fit individuals observed by Takeshita et al. (1986).

The intravenous injection of epinephrine $(E)$ promotes the efflux of potassium from the heart (Welty and Read, 1963) and affects the characteristic of receptor as described above. If the different levels of plasma $\mathrm{E}$ concentrations in response to orthostatic challenge exist among individuals, this may explain the various threshold of vasoconstrictor response in this study. Although norepinephrine (NE), E, vasopressin, and renin activity were elevated by various forms of orthostatic challenge (Convertino, 1993), the $\mathrm{NE}$ and $\mathrm{E}$ concentrations in the supine and standing position were not correlated with fitness level (Kohrt et al., 1993). It is most likely due to the evidence that these neurotransmitter concentrations reflect the leaking into plasma from sympathetic nerve terminals (Esler et al., 1984) and representing a rough index of sympathetic nerve activity. Thus these evidences do not negate a role of plasma electrolyte as an affecting factor of $\mathrm{CP}$ baroreflex.

From the stand point of central nervous system, nonspecific change should be considered. The $\mathrm{CP}$ baroreflex seems to be acting as a feedforward element in anticipative blood pressure regulation (Mack et al., 1988). It could be explained by the evidence for the existence of central command mechanisms that contribute to the autonomic responses at the beginning of exercise or some behaviors as seen in the feature of the defence reaction (Korner, 1983).

The major finding of this study was that the cardiopulmonary baroreflex stimulus-response relationship was shifted to the lower operational range of SV in physically fit individuals. The shift may represent a resetting of the cardiopulmonary mechanoreceptor.

Finally, transient and prolonged response in FVR must be distinguished. When standing is prolonged, the initial vasoconstriction in peripheral vasculature may not always be sufficient to maintain mean arterial pressure or to avoid syncope. Further research is needed to provide a better understanding of reflex control of the circulation under orthostatic challenge.

Acknowledgements. The authors thank the subjects for their willing cooperation during the experiments and Mutsuhiro Fujiwara for his management of the artificial climatic chamber.

\section{References}

Abboud FM, Thames MD (1983) Interaction of cardiovascular reflexes in circulatory control. In Shepherd JT, Abboud FM eds. Handbook of Physiology. The Cardiovascular System. Peripheral Circulation and Organ Blood Flow. Bethesda MD: Am Physiol Soc, sect 2, vol 3, pt 2, chapt 19,675-753 
Balke B (1961) An experimental study of "physical" fitness of air force personnel. US Armed Forces Med J 10(6): 675-688

Broźek J, Grande F, Anderson JT, Keys A (1963) Densitometric analysis of body composition: Revision of some quantitative assumptions. Ann NY Acad Sci 110: $113-140$

Clausen JP, Klausen K, Rasmussen B, Jensen JT (1973) Central and peripheral circulatory changes after training of the arms and legs. Am J Physiol 225(3): 675-682

Convertino VA (1991) Blood volume: its adaptation to endurance training. Med Sci Sports Exerc 23(12): 1338-1348

Convertino VA (1993) Endurance exercise training: conditions of enhanced hemodynamic responses and tolerance to LBNP. Med Sci Sports Exerc 25(6): 705-712

Convertino VA, Montgomery LD, Greenleaf JE (1984) Cardiovascular responses during orthostasis:Effect of an increase in $\mathrm{VO}_{2 \max }$. Aviat Space Environ Med 55: 702-708

Esler E, Jennings G, Korner P, Blombery P, Sacharias, $\mathrm{N}$, Leonard P (1984) Measurement of total and organic-specific norepinephrine kinetics in humans. Am J Physiol 247 (Endocrinol Metab 10): E21-E28

Fujimoto S, Watanabe T, Sakamoto A, Yukawa K, Morimoto K (1968) Studies on the physical surface area of Japanese: Part 18 calculation formulas in three stages over all age (in Japanese). Jap J Hyg 23(5): $443-450$

Johnson JM, Rowell LB, Niederberger M, Eisman MM (1974) Human splanchnic and forearm vasoconstrictor responses to reductions of right atrial and aortic pressures. Circ Res 34: 515-524

Kohrt WM, Spina RJ, Ehsani AA, Cryer PE, Holloszy JO (1993) Effects of age, adiposity, and fitness level on plasma catecholamine responses to standing and exercise. J Appl Physiol 75(4): 1828-1835

Korner PI (1983) Central nervous control of autonomic cardiovascular function. In Berne RM eds. Handbook of Physiology. The Cardiovascular System. The Heart. Bethesda MD: Am Physiol Soc, sect 2, vol 1, chapt 20,691-739

Kubicek WG, Karneigis JM, Patterson RP, Witsoe DA, Mattson RH (1966) Development and evaluation of an impedance cardiac output system. Aerosp Med 37: $1208 \cdot 1212$

Kunze DL '(1985) Role of baroreceptor resetting in cardiovascular regulation: acute resetting. Federation Proceedings 44(8): 2408-2411

Levine BD, Lane LD, Buckey JC, Friedman DB, Blomqvist CG (1991) Left-ventricular pressure-volume and Frank- Starling relations in endurance athletes: implications for orthostatic tolerance and exercise performance. Circulation 84(3): 1016-1023

Lightfoot JT, Claytor RP, Torok DJ, Journell. TW,
Fortney SM (1989) Ten weeks of aerobic training do not affect lower body negative pressure responses. J Appl Physiol 67(2): 894-901

Mack GW, Convertino VA, Nadel ER (1993) Effect of exercise training on cardiopulmonary baroreflex control of forearm vascular resistance in humans. Med Sci Sports Exerc 25(6): 722-726

Mack G, Nose H, Nadel ER (1988) Role of cardiopulmonary baroreflexes during dynamic exercise. J Appl Physiol 65(4): 1827-1832

Mack GW, Shi X, Nose H, Tripathi A, Nadel ER (1987) Diminished baroreflex control of forearm vascular resistance in physically fit humans. J Appl Physiol 63(1): $105-110$

Mark AL, Mancia G (1983) Cardiopulmonary baroreflexes in humans. In Shepherd JT, Abboud FM eds. Handbook of Physiology. The Cardiovascular System. Peripheral Circulation and Organ Blood Flow. Bethesda MD: Am Physiol Soc, sect 2, vol 3, pt 2, chapt 21, $795-813$

Mifflin SW, Kunze DL (1982) Rapid resetting of low pressure vagal receptors in the superior vena cava of the rat. Circ Res 51(2): 241-249

Mohanty PK, Thames MD, Arrowood JA, Sowers JR, McNamara C, Szentpetery S (1987) Impairment of cardiopulmonary baroreflex after cardiac transplantation in humans. Circulation 75(5): 914-921

Nadel ER, Cafarelli E, Roberts MF, Wenger CB (1979) Circulatory regulation during exercise in different ambient temperatures. J Appl Physiol 46(3): 430-437

Nagamine S, Suzuki S (1964) Anthropometry and body composition of Japanese young men and women. Hum Biol 36: 8-15

Nishiyasu T, Shi X, Mack GW, Nadel ER (1993) Forearm vascular responses to baroreceptor unloading at the onset of dynamic exercise. J Appl Physiol 75(2): 979-985

Raven PB, Rohm-Young D, Blomqvist CG (1984) Physical fitness and cardiovascular response to lower body negative pressure. J Appl Physiol: Respirat Environ Exercise Physiol 56(1): 138-144

Saum WR, Ayachi S, Brown AM (1977) Actions of sodium and potassium ions on baroreceptors of normotensive and spontaneously hypertensive rats. Circ Res 41(6): 768-774

Shvartz E, Convertino VA, Keil LC, Haines RF (1981) Orthostatic fluid-electrolyte and endocrine responses in fainters and nonfainters. J Appl Physiol 51(6): 14041410

Svedenhag J (1985) The sympatho-adrenal systems in physical conditioning. Significance for traininginduced adaptations and dependency of the training state. Acta Physiol Scand 125: 1-73 (Suppl)

Takeshita A, Jingu S, Imaizumi T, Yamamoto K, Koyanagi S, Nakamura M (1986) Augmented cardio. 
pulmonary baroreflex control of forearm vascular resistance in young athletes. Circ Res 59: 43-48

Welty JD, Read WO (1963) Studies on some cardiac effects of taurine. J Pharmacol Exp Ther 144: 110-115

Whitney RJ (1953) The measurement of volume changes in human limbs. J Physiol 121: 1-27

Zoller RP, Mark AL, Abboud FM, Schmid PG, Heistad DD (1972) The role of low pressure baroreceptors in reflex vasoconstrictor responses in man. J Clin Invest
51: $2967-2972$

Received: April 10, 1995

Accepted: May 11, 1995

Correspondence to: Haruki Hayashi, Department of Anatomy and Anthropology, School of Medicine, University of Occupational and Environmental Health, 1-1 Iseigaoka, Yahatanishi-ku, Kitakyushu 807, Japan 